\title{
A DESCENTRALIZAÇÃO EM CURSO DAS POLÍTICAS PÚBLICAS DE ESPORTE E DE LAZER NO ESTADO DO PIAUÍ
}

\author{
Edmilson Santos dos Santos
}

Universidade Federal do Vale do São Francisco, Petrolina, Pernambuco, Brasil.

\begin{abstract}
Resumo
Este trabalho tem por objetivo analisar a descentralização bottom-up das políticas públicas de esporte e de lazer no estado do Piauí, no ciclo eleitoral 2013/2016. Três aspectos foram contemplados: a análise do financiamento, a análise da estrutura administrativa de implementação das políticas públicas de esporte e de lazer e, por último, a produção legislativa no âmbito das leis orgânicas. Os dados sobre a Função Desporto e Lazer (FDL) foram colhidos junto à Secretaria do Tesouro Nacional, a estrutura administrativa e lei orgânica diretamente do site das prefeituras. A forte adesão dos municípios ao gasto na FDL não pode ser explicada pela estrutura administrativa e legislativa.
\end{abstract}

Palavras-chave: Esporte. Lazer. Descentralização. Municipalização. Federalismo.

\section{THE ONGOING DECENTRALIZATION OF SPORT AND LEISURE PUBLIC POLICIES IN THE STATE OF PIAUÍ}

\begin{abstract}
This study aimed to analyze the bottom-up decentralization of sport and leisure public policies in the state of Piauí, during the 2013/2016 electoral cycle. Three aspects have been approached: analysis of funding, analysis of the administrative structure of the implementation of sport and leisure public policies and, finally, the legislative production in the sphere of organic laws. Data on Function Sports and Leisure (FDL) has been gathered with the National Treasure Department, the administrative structure and organic law are available on the municipal governments' websites. The strong adherence of municipalities to the investment in FDL cannot be explained through administrative and legislative structure.
\end{abstract}

Keywords: Sport. Leisure. Decentralization. Municipalization. Federalism.

\section{LA DESCENTRALIZACIÓN EN CURSO DE LAS POLÍTICAS PÚBLICAS DE DEPORTE Y DE OCIO EN EL ESTADO DE PIAUÍ}

\begin{abstract}
Resumen
El presente estudio tuvo como objetivo analizar la descentralización ascendente de las políticas públicas de deporte y ocio en el estado de Piauí, durante el ciclo electoral 2013/2016. Tres aspectos se han abordado: el análisis de la financiación, el análisis de la estructura administrativa de la implementación de las políticas públicas de deporte y ocio y, finalmente, la producción legislativa en el ámbito de las leyes orgánicas. Los datos sobre FDL se han reunido con el Departamento Nacional del Tesoro, la estructura administrativa y la ley orgánica son disponible en los sitios web de los gobiernos municipales. La fuerte adhesión de los municipios a la inversión en FDL no se puede explicar a través de la estructura administrativa y legislativa.
\end{abstract}

Palabras clave: Deporte. Ocio. Descentralización. Municipalización. Federalismo. 


\section{Introdução}

Há dois elementos que precisam ser compatibilizados no debate sobre os direitos sociais: o primeiro trata-se de sua existência de forma clara no texto constitucional; o segundo, por sua vez, diz respeito à estrutura administrativa para efetivação do direito ${ }^{1}$. Nesse caso, o impacto institucional do federalismo traz consequências importantes à análise do gasto realizado pelos municípios nas políticas públicas de esporte e de lazer.

A descentralização ocorrida pós-Constituição Federal de 1988 (BRASIL, 1988) distribuiu recursos e funções administrativas entre níveis de governo (LEITE, 2009). Porém, em algumas áreas, a ambiguidade de competência ajudou a produzir lacunas assistenciais (AFONSO; LOBO, 1996). Quanto à distribuição de funções administrativas, a Constituição Federal de 1988 (CF/88) não auferiu a qualquer dos entes federados (União, estados, Distrito Federal e municípios) obrigatoriedade (competência exclusiva) na implementação de políticas públicas de esporte e de lazer (e, também, não aprece entre as competências comuns), apesar de garantir o direito ao acesso dos cidadãos a eles (Art. 217 da CF/88). Portanto, a inação não constitui uma ilegalidade contra o Estado brasileiro, mas sim um resultado possível de nosso federalismo desenhado pelo texto constitucional.

Do ponto de vista do comportamento dos governos, há quatro possibilidades de atuação dos governos executivos no que concerne às políticas de esporte e de lazer: a execução autônoma de cada um dos entes federados (podendo produzir, inclusive, a concorrência pela melhor política) com sua própria política; a cooperação entre os entes federados na implementação de uma política específica do ente federado superior (podendo ser o estado ou a União); a transferência de responsabilidade à sociedade civil, especialmente ao terceiro setor; ou a inação.

A temática do esporte foi recepcionada através da Seção III, do Capítulo III, Da Ordem Social. À vista disso, o Art. 217 estabelece que "É dever do Estado fomentar práticas desportivas formais e não-formais, como direito de cada um [...]". O fomento às práticas esportivas determina apenas que os governos estimulem, incentivem ou despertem o interesse a elas. Campanhas publicitárias poderiam muito bem cumprir esse papel. Não está posto, por exemplo, que o Estado tenha que desempenhar atividades finalísticas (SANTOS; FREITAS, 2015).

Levando em consideração a estrutura constitucional do Estado brasileiro, parece ser forçoso que os entes federados tenham algum tipo de obrigação afirmada pelo texto constitucional em relação ao esporte e ao lazer. Diante da inexistência de atribuições aos municípios para essas duas agendas (esporte e lazer), a inação torna-se um comportamento esperado dentro da estrutura federalista brasileira, seja na descentralização de sua própria agenda política (bottom-up), seja na descentralização da agenda de um ente superior (topdown $)^{2}$.

O gasto realizado na descentralização das políticas de esporte e de lazer por parte dos municípios não tem sido objeto de análise comparativa pela literatura da área de políticas públicas de esporte e de lazer. Apesar da qualidade e importância da produção, ela tem se debruçado sobre outros aspectos das políticas públicas. Ora analisando o comportamento do governo federal (ATHAYDE; MASCARENHAS; SALVADOR, 2015; CASTRO, 2016; FIGUERÔA, 2014; ALMEIDA; MARCHI JR., 2010; VERONEZ, 2007), ora fazendo análises de municípios específicos (GRASSO; ISAYAMA, 2017; BORGES; TONINI, 2011;

\footnotetext{
${ }^{1}$ Pelo menos no que se refere ao esporte, o Art. 24 da CF/88 garantiu competência concorrente entre União, estados, Distrito Federal e municípios. Se há um direito a ser perseguido, não há uma instituição obrigada a efetiválo. O tratamento do lazer não lhe garantiu nem competência concorrente e nem exclusiva de algum ente federado (BRASIL, 1988).

${ }^{2}$ Para melhor análise da descentralização top-down e bottom-up, ver Sabatier (1986).
} 
RIBEIRO, 2013; VENTURIM; BORGES; SILVA, 2013; SILVA, 2014). Em termos de descentralização, o trabalho de Santos, Starepravo e Souza Neto (2015) analisou a descentralização do Programa Segundo Tempo na região Nordeste (descentralização topdown). A descentralização bottom-up, foi privilegiada no trabalho de Santos e Hirata (2017).

Diante desse cenário, o presente trabalho buscou analisar a descentralização bottom-up das políticas públicas de esporte e de lazer através da análise dos gastos na Função Desporto e Lazer (FDL), no estado do Piauí, no mais recente ciclo eleitoral 2013/2016. Para isso, três aspectos foram contemplados: (1) a análise do financiamento; (2) a análise da estrutura administrativa de implementação das políticas públicas de esporte e de lazer; (3) e, por último, a produção legislativa no âmbito das leis orgânicas.

\section{Métodos}

Este trabalho de natureza descritiva exploratória buscou analisar a descentralização bottom-up dos gastos da Função Desporto e Lazer, no estado do Piauí, no ciclo eleitoral 2013/2016. Alguns aspectos foram analisados: o financiamento na FDL, da estrutura administrativa à implementação das políticas públicas de esporte e de lazer, e, por último, a produção legislativa no âmbito das leis orgânicas. O gasto, a estrutura de governo e o escopo legislativo são variáveis importantes para melhor compreensão da descentralização das políticas públicas, pois, como revela Hall e Taylor (2003), as instituições podem oferecer informações importantes sobre o comportamento dos atores.

As informações referentes a este estudo vieram de diferentes fontes. Os dados sobre a FDL foram colhidos junto a Secretaria do Tesouro Nacional, que disponibiliza no Sistema de Informações Contábeis e Fiscais do Setor Público Brasileiro (SICONFI) os valores investidos pelos municípios na FDL. A coleta das informações foi realizada entre março e maio de 2017.

A FDL se refere à classificação do gasto orçamentário realizado em políticas de esporte e de lazer e foi estabelecida através da Portaria $n^{\circ}$. 42, do Ministério da Gestão e Orçamento (BRASIL, 1999). A desagregação dos dados da FDL permitiu classificar as despesas em quatro subfunções: Desporto Rendimento; Desporto Comunitário; Lazer e demais subfunções do Esporte e Lazer. Como a subfunção "demais subfunções do Esporte e Lazer" não especifica uma área de atuação, não será considerada na análise dos percentuais. Posto isto, ressaltarmos que estamos considerando apenas os recursos liquidados (regulada pelo Art. 63, da Lei $\mathrm{n}^{\circ}$. 4.320/1964). Para efeitos deste trabalho, portanto, desconsideramos a quarta subfunção, até porque ela não aponta, com clareza, um determinado objeto a ser contemplado. As despesas na FDL são dos recursos executados, independentes da origem do recurso para implementação da ação. Para garantir a comparabilidade das informações fiscais, os valores referentes ao FDL foram deflacionados pelo Índice de Preços ao Consumidor (IPCA).

As informações sobre a estrutura administrativa de primeiro escalão responsável pelas políticas de esporte e de lazer e sobre as leis orgânicas foram buscadas diretamente no site das prefeituras, no período de novembro a dezembro de 2016. Depois, a estrutura administrativa das prefeituras foi classificada em três níveis: (a) prefeituras que apresentavam secretarias exclusivas de esporte e/ou lazer (SE); (b) prefeituras que apresentavam a agenda do esporte sendo compartilhada com outra secretaria $(\mathrm{ScO})$; (c) prefeituras que não apresentam órgão de primeiro escalão (SemS).

Por sua vez, a composição da amostra das leis orgânicas foi feita de forma aleatória. Estabelecemos o percentual da amostragem [30\%; $\mathrm{n}=66$; (exato 29,46\%)] e fizemos a captura. Considerando que muitas prefeituras não disponibilizam essa informação em seus sites (45,53\% não apresentavam o link de acesso à lei orgânica), seguimos a captura até alcançar a amostragem estipulada. Três níveis de informações foram classificados: (a) o tema 
do esporte e do lazer entre as competências privativas dos municípios; (b) o tema do esporte e do lazer entre as competências comuns dos municípios; (c) indicação de percentual da receita comprometida com as políticas públicas de esporte e de lazer.

Todas as informações compuseram um banco de dados único (em planilha Excel) contendo a listagem dos municípios do estado do Piauí, sendo esta registrada pelo Instituto Brasileiro de Geografia e Estatística (IBGE), bem como a classificação da estrutura de governo de primeiro escalão, as classificações referentes às leis orgânicas e o gasto na função e subfunções. O uso da estatística descritiva permitiu identificar valores totais e percentuais.

\section{Análise dos resultados}

A existência de uma forte adesão dos municípios à realização de gasto na FDL implica em conhecermos a estrutura administrativa colocada à disposição dessa política. Nessa análise, encontramos três cenários no que diz respeito à estrutura administrativa de primeiro escalão. No primeiro, estão aqueles municípios que possuem órgão exclusivo de implementação de políticas públicas de esporte e/ou lazer [secretaria municipal de esporte ou de esporte e lazer $(\mathrm{SE})]$. Realidade vivida por 38,39\% $(\mathrm{n}=86)$ dos municípios. No segundo, a temática esporte (e/ou lazer) é acompanhada por outras $(\mathrm{ScO})$. Portanto, são 52 municípios que se encaixam nesse quadro $(23,21 \%)$. Elas estão associadas a diferentes outras áreas de atuação do governo. Por último, temos aquelas cidades que não apresentam nenhum órgão de primeiro escalão à implementação de políticas de esporte e de lazer nos municípios do estado do Piauí (SemS), 38,39\% ( $\mathrm{n}=86)$.

A vantagem de ter estrutura própria, em tese, é a dotação orçamentária construída diretamente pela pauta da secretaria, pois envolve constituir estrutura de poder que tem relação direta com os apoios necessários à governabilidade. Compondo com outras temáticas haverá disputas orçamentárias por recursos sempre escassos.

A ausência de secretaria não significa que essa agenda não possa ser contemplada. Por outro lado, longe de significar uma anormalidade, ela está de acordo com a autonomia federativa. A estrutura administrativa é discricionária do partido que assume a prefeitura e não há elementos probatórios de que a temática esporte e lazer sejam ideias empoderadas pela sociedade de forma a garantir, obrigatoriamente, estrutura administrativa de primeiro escalão. Mas os gastos governamentais podem fornecer informações importantes sobre o desempenho dos governos, como destaca Ribeiro (2006).

O percentual de municípios que fizeram algum tipo de gasto na FDL, no período, foi de $96,42 \%(\mathrm{n}=216)$. Apenas oito municípios não fizeram nenhum tipo de gasto na FDL. Três deles tinham secretaria exclusiva, três não tinham secretarias e dois municípios tinham a secretaria de esporte junto com outras áreas. Esse quadro revela a complexidade da alocação de recursos para políticas públicas de esporte e de lazer numa área não regulada por norma superior. A inação em políticas bottom-up não está associada apenas à inexistência de pasta.

A adesão ao gasto na FDL não se diferencia por estrutura administrativa. A realização de algum gasto no período foi de $96,51 \%$ para os municípios com secretaria exclusiva e sem órgão de primeiro escalão, e $96,15 \%$ para aqueles cuja pasta é compartilhada por outra política. Isso significa que a adesão acontece independentemente do tipo de organização político-administrativa. Considerando o elevado grau de adesão, parece que a agenda do esporte e do lazer possui forte reconhecimento junto à comunidade.

Os municípios que fizeram adesão ao FDL, durante todo o período, foram de 72,32\% ( $\mathrm{n}=162$ ). Entre os tipos de organização político-administrativa, os resultados não apresentaram grandes distorções: secretaria exclusiva, 39,51\% $(n=64)$; secretaria com outras pastas, $25,93 \%(n=42)$; sem órgão de primeiro escalão, 24,57\% $(n=56)$. Esse resultado 
reforça a percepção de que a agenda esportiva possui valor às comunidades independentemente do tipo de organização político-administrativa das prefeituras.

Os níveis de adesão variaram muito pouco ao longo do período. Nos anos de 2013 e 2014, as adesões foram as mesmas $(87,95 \%$; $\mathrm{n}=197)$. O número de municípios que implementou um gasto da gestão anterior é o mesmo da gestão que estabeleceu seu próprio orçamento, em 2014. Ou seja, a manipulação orçamentária pelos projetos políticos que assumiram a gestão 2013/2016 não influenciou a adesão ao gasto na FDL. Em 2015, esse valor teve leve queda, $86,61 \%(\mathrm{n}=194)$. Queda essa que continuou no ano seguinte, $84,38 \%$ $(n=189)$. Mesmo com a queda da adesão durante o período a participação permaneceu elevada.

Os municípios com SE parecem ter capacidade financeira melhor para o gasto na FDL. Em todos os cenários, o volume de recurso é maior. Nos outros cenários, essa prevalência se equilibra. Em 2013 e 2016, há maior volume alocado na FDL pelos municípios ScO e, em 2014 e 2015, para os SemS. No entanto, o menor número de cidades ScO indica para todos os cenários, inclusive aqueles em que o volume total/ano é menor para essa estrutura administrativa, que os valores alcançados por essas prefeituras são, de fato, superiores aos SemS. Nesse caso, ter órgão de primeiro escalão pressiona por maior volume financeiro investido.

Tabela 1. Gasto na FDL por estrutura político-administrativa dos municípios do PI no período de 2013/2016. (em milhões)

\begin{tabular}{|c|c|c|c|c|c|c|c|c|}
\hline \multirow{2}{*}{ Estrutura } & \multicolumn{2}{|c|}{2013} & \multicolumn{2}{c|}{2014} & \multicolumn{2}{c|}{2015} & \multicolumn{2}{c|}{2016} \\
\cline { 2 - 9 } & $\mathrm{N}$ & $\mathrm{R} \$$ & $\mathrm{~N}$ & $\mathrm{R} \$$ & $\mathrm{~N}$ & $\mathrm{R} \$$ & $\mathrm{~N}$ & $\mathrm{R} \$$ \\
\hline $\mathrm{SE}$ & 75 & 10,51 & 77 & 16,95 & 76 & 10,15 & 77 & 12,4 \\
\hline $\mathrm{ScO}$ & 49 & 9,55 & 48 & 7,99 & 50 & 6,61 & 45 & 7,4 \\
\hline $\mathrm{Sem} S$ & 72 & 4,39 & 71 & 10,01 & 67 & 10,06 & 67 & 5,06 \\
\hline
\end{tabular}

Fonte: Dados da pesquisa; SICONFI.

A norma em vigor no Brasil não estabelece obrigações quanto ao gasto na FDL e nem qual subfunção deve obter investimentos e qual não deve (SANTOS; FREITAS, 2015). Essa definição é estritamente política. $O$ fato de não termos informações sobre o gasto no desporto educacional não nos impede de fazer algumas ponderações importantes.

Como podemos observar na Tabela 1 , há uma grande variação no total de gasto na FDL ao longo do período em todas as estruturas. Em dois cenários (SE e SemS), considerando a entrada e a saída do ciclo eleitoral, houve crescimento de receita ao longo do período (17,98\% e 15,26\%, respectivamente). No entanto, no primeiro, o crescimento foi acompanhado por adesão (de 75 para 77 prefeituras que realizaram gasto na FDL), no segundo, por retração (de 72 para 67). Nesse caso, o crescimento do segundo é muito mais substantivo, pois é alcançado com retrações no número de adesões, até porque se exige elevação no volume de recursos.

Isto demonstra que, entre as cidades que não possuem estrutura administrativa de primeiro escalão, o gasto teve crescimento superior as duas outras estruturas. No entanto, é importante observar que a variação das cidades SemS é muito significativa no comportamento dos agentes. Em 2014 e 2015, o total investido é o dobro do ano de 2013 e cai pela metade no final do ciclo eleitoral. Para essas cidades, parece que a vulnerabilidade da agenda é maior.

$\mathrm{Na}$ Tabela 2, por exemplo, podemos observar que todos os municípios, independentemente da organização político-administrativa, alocam a maior parte dos recursos da FDL na sDC. É uma preferência bastante consolidada e que tem apenas no ano de 2015 o pior resultado no grupo SemS. 
Outro aspecto importante é que os policy makers preferem investir na sL do que na sDR. Em todos os cenários do grupo SE e SemS, o percentual de gasto na sDR foi menor do que na sL. Ou seja, o esporte rendimento é uma prioridade periférica nas disputas por recursos nos municípios do estado do Piauí. Apenas no grupo ScO, encontramos dois cenários em que o percentual de gasto no esporte rendimento foi maior que no lazer.

Em linhas gerais, portanto, consolida-se uma perspectiva de gasto por parte dos municípios do Piauí, no ciclo-eleitoral de 2013/2016, que: (a) priorizam o esporte comunitário, (b) o lazer é a segunda opção de gasto dos municípios, (c) o esporte rendimento faz parte do campo de preocupações políticas por parte dos governos municipais. Infelizmente, o gasto com o desporto educacional, nos termos estabelecidos pela Lei Pelé (BRASIL, 2007), não é registrado na FDL. Mas, como em todos os municípios, a educação física está associada à oferta do ensino fundamental, pois se presume que existam investimentos mais constantes no desporto educacional.

Tabela 2. Percentual de investimento na FDL por subfunção

\begin{tabular}{|l|c|c|c|c|}
\hline $\begin{array}{l}\text { Estrutur } \\
\text { a }\end{array}$ & Ano & \%sDR & \%sDC & \%sL \\
\hline \multirow{4}{*}{ SE } & 2013 & 8,61 & 73,93 & 11,17 \\
\cline { 2 - 5 } & 2014 & 5,72 & 73,14 & 12,74 \\
\cline { 2 - 5 } & 2015 & 3,90 & 67,12 & 12,70 \\
\cline { 2 - 5 } & 2016 & 4,33 & 65,79 & 22,33 \\
\hline \multirow{4}{*}{ ScO } & 2013 & 5,87 & 67,82 & 7,27 \\
\cline { 2 - 5 } & 2014 & 11,67 & 72,54 & 9,38 \\
\cline { 2 - 5 } & 2015 & 6,41 & 67,74 & 9,69 \\
\cline { 2 - 5 } & 2016 & 5,62 & 78,57 & 5,52 \\
\hline \multirow{4}{*}{ SemS } & 2013 & 2,48 & 77,25 & 14,80 \\
\cline { 2 - 5 } & 2014 & 0,79 & 81,96 & 17,25 \\
\cline { 2 - 5 } & 2015 & 1,55 & 47,79 & 6,86 \\
\cline { 2 - 5 } & 2016 & 2,65 & 78,79 & 14,79 \\
\hline
\end{tabular}

Fonte: Dados de pesquisa: SICONFI.

O fato de não existir norma federal patrocinando o engajamento dos municípios na realização de gastos na FDL, sua efetiva realização pode sinalizar a existência de norma, no âmbito dos municípios, que pode induzir tal comportamento. A lei orgânica dos municípios é a principal norma que baliza o comportamento do agente local no que se refere a suas atribuições para com o desenvolvimento das diferentes políticas.

A CF/88 não indicou o esporte e o lazer como atribuições dos municípios, mas colocou no Inciso IX do Art. 24 a possibilidade de os municípios legislarem de forma concorrente nessa matéria. Isso significa que o ator responsável pela efetivação do direito, Art. 217, são os legisladores locais e não o poder executivo.

Dessa forma, ao observarmos a produção legislativa no âmbito das leis orgânicas na amostra do estudo, foi possível observar que:

(a) apenas $9,1 \%(\mathrm{n}=6)$ colocaram como responsabilidade privativa dos municípios a implementação de políticas públicas de esporte e de lazer. Portanto, os legisladores não responsabilizaram o município pela implementação de políticas públicas de esporte. Com isso, ampliam-se os incentivos à inação;

(b) apenas 4,5\% colocaram que as políticas são também de responsabilidade dos municípios (competências comuns). Em tese, a cooperação com o governo federal é 
dependente dos municípios reconhecerem atribuição comum. Se eles não reconhecem a atribuição como sendo comum a eles, amplificam-se os incentivos à inação;

(c) apenas um município (Curralinho) estabeleceu percentual do orçamento à efetivação de políticas públicas de esporte e de lazer: Art. 259, "O município gastará pelo menos 3\% (três por centos) de sua receita com o esporte amador e recreação" (CURRALINHO, 1997). No ciclo eleitoral, o município não realizou investimentos no ano de 2016 e jamais investiu 3\% de sua receita. Esse resultado sinaliza que propostas incompatíveis com a cultura institucional na área do esporte (e, talvez, com a capacidade fiscal dos municípios) não contribuem para ampliação da oferta da política.

Dos municípios que não esboçaram inclinação para ter de forma privativa o comprometimento com a agenda do esporte e do lazer e, por conta disso, não estabeleceram percentuais da receita de investimento, $72,32 \%(\mathrm{n}=162)$ fizeram investimentos em todo o período eleitoral. De forma geral e à revelia do que estabelecem as leis orgânicas, os municípios do Piauí reconhecem a agenda esportiva e de lazer como algo importante à comunidade.

\section{Considerações finais}

A inexistência de dados comparativos com outros estados represa nossa capacidade de reflexão sobre as variáveis que efetivamente impactam na produção das políticas de esporte e de lazer do ponto de vista nacional, mas os resultados aqui encontrados indicam a efetiva municipalização das políticas públicas de esporte e de lazer no estado do Piauí.

No Piauí, a participação dos municípios no financiamento do esporte e do lazer tem sido efetiva em número de prefeituras. A existência ou não de órgão de primeiro escalão para a efetivação das políticas não teve impacto no que diz respeito aos investimentos realizados pelas prefeituras municipais. Contudo, esse fator (variável) não impediu que os governos fizessem investimentos em políticas públicas de esporte e lazer.

Não só os investimentos foram realizados, como os recursos dos municípios com SE e SemS tiveram aumentos positivos ao longo do período. Ou seja, a agenda continuou se fortalecendo no estado do Piauí. Isso indica valorização crescente da política dentro do estado.

Os efeitos aqui encontrados vão ao encontro das premissas colocadas pelo sistema federalista. Primeiro, a distribuição de autoridade política entre os entes federados, no nosso caso, os municípios. Isso permitiu que, independentemente do governo federal, eles pudessem decidir sobre suas agendas (SOUZA, 1998). Talvez não seja demasiado considerar que a descentralização das políticas públicas de esporte e de lazer, registrada através do gasto na FDL, anuncie certa responsividade dos governos municipais com essas políticas. Nessa direção, Arretche (2002) coloca na descentralização a motivação para esse tipo de comportamento por parte dos municípios. No entanto, seu ciclo deveria ser completado com a eficiência do gasto e com sua transparência. Para esse estudo, essas duas variáveis não foram investigadas, mas representam um próximo passo importante para melhor compreensão desse cenário.

Segundo, analisando estritamente a existência do recurso, que denota apreciação com a agenda, foi possível observar que a ambiguidade de competência não impediu que ela fosse premiada pelos municípios. No entanto, essa liberdade alocativa pode produzir lacunas de políticas ou desigualdade na oferta, principalmente, quando se leva em consideração as desigualdades ficais entre os municípios brasileiros. O fato de não existir elevada lacuna no Piauí não implica, necessariamente, a uma distribuição desigual desses bens públicos. Esse aspecto também garante fôlego para uma agenda de pesquisa futura. 
Terceiro, infelizmente, não temos parâmetros comparativos nacionais de forma a começar a desenhar o que seria um padrão ótimo de investimento. Nesse caso, teríamos que avançar no debate sobre o federalismo fiscal, pois esse elemento pode produzir distorções importantes na oferta das políticas (AFONSO; LOBO, 1996). Como destaca Arretche (2005), é a capacidade fiscal dos municípios que determina em boa medida a formulação das políticas públicas.

Quarto, permitimo-nos aqui uma digressão importante com relação ao peso das normas no alinhamento dos comportamentos, algo imprescindível ao sistema federativo. De um lado, temos lacuna nas normas que induzem à inação dos municípios em relação ao gasto na FDL. De outro, temos a realidade fática do gasto na FDL que demonstra o contrário. Esse encaixe entre legislação e oferta de políticas públicas de esporte e de lazer precisaria ser melhor detalhado em estudos futuros.

Para finalizar, a compreensão mais adequada de como se formula, se implementa e se avalia as políticas públicas de esporte e de lazer, no âmbito municipal, dependente, ainda, de exames comparativos da capacidade de gasto na FDL. Portanto, necessitamos de mais esforços às análises do gasto dos municípios na FDL por parte da policy communities da área do esporte e do lazer.

\section{Referências}

AFONSO, J.R.R.; LOBO, T. Descentralização fiscal e participação em experiências democráticas retardatárias. Planejamento e Políticas Públicas, Brasília, n. 14, p. 3-36, 1996.

ALMEIDA, B. S.; MARCHI JÚNIOR, W. O financiamento dos programas federais de esporte e lazer no Brasil (2004 a 2008). Movimento, Porto Alegre, v. 16, n. 4, p. 73-92, 2010.

ARRETCHE, M. Quem taxa e quem gasta: a barganha federativa na federação brasileira. Revista de Sociologia e Política, v. 24, n. 1, p. 69-85, 2005.

ARRETCHE, M. Federalismo e relações intergovernamentais no Brasil: a Reforma dos Programas Sociais. Dados, Rio de Janeiro, v. 45, n. 3, p. 431-458, 2002.

ATHAYDE, P.; MASCARENHAS, F.; SALVADOR, E. Primeiras aproximações de uma análise do financiamento da política nacional de esporte e lazer no Governo Lula. Revista Brasileira de Ciências do Esporte, v. 37, n. 1, p. 2-10, 2015.

BORGES, C. N. F.; TONINI, G. T. O incentivo ao esporte de alto rendimento como política pública: influências recíprocas entre cidade e esporte. Revista Brasileira de Ciências do Esporte, v. 34, n. 2, 2011.

BRASIL. Constituição da República Federativa do Brasil. Brasília, DF: Senado Federal: Centro Gráfico, 1988. 292 p.

BRASIL. Lei no 4.320, de 17 de março de 1964. Disponível em: <http://www.planalto.gov.br/ccivil_03/Leis/14320.htm> Acesso em: 10 de jan. 2018.

BRASIL. Ministério do Planejamento, Orçamento e Gestão. Portaria n. ${ }^{\circ} 42$, de 14 de abril de 1999. Diário Oficial [da] República Federativa do Brasil, Brasília, DF, 14 abr. 1999a. Disponível em: <http://ftp.fnde.gov.br/web/siope/leis/P42_MPOG_14-041999.pdf>. Acesso em: 05 abr. 2017. 
BRASIL. Lei $\mathbf{n}^{\mathbf{1}}$ 11.472, de 2 de maio de 2007. Disponível em: <http://www.planalto.gov.br/CCIVIL/_Ato2007-010/2007/Lei/L11472.htm\#art1〉. Acesso em: 03 jul. 2018.

CASTRO, S. B. E. de. Políticas públicas para o esporte e lazer e o ciclo orçamentário brasileiro (2004-2011): prioridades e distribuição de recursos durante os processos de elaboração e execução orçamentária. 378 f. 2016. Tese (Doutorado em Educação Física) Universidade Federal do Paraná, Curitiba, 2016.

FIGUERÔA, K. M. et al. Planejamento, ações e financiamento para o esporte em tempos de megaeventos. Motrivivência, v. 26, n. 42, p. 55-71, 2014.

IBGE. Instituto Brasileiro de Geografia e Estatística. Perfil dos Municípios Brasileiros 2006. Disponível em: <http://www.ibge.gov.br>. Acesso em: 10 mar. 2016.

LEITE, C.K.S. Descentralização das políticas sociais no Brasil: o lugar dos estados no processo de municipalização. Revista Política Hoje, v. 18. n. 2, p. 306-341, 2009.

LOPES, T.B.; SANTOS, D.C.S.; ISAYAMA, H.F. Reflexões Sobre a Política Social e a Política de Lazer no Brasil. Licere, Belo Horizonte, v. 19, n. 3, p. 332-362, 2016.

RIBEIRO, Olívia Cristina Ferreira. Ferreira. Um estudo das políticas públicas de lazer de Brotas/SP. Licere, Belo Horizonte, v. 16, n. 3, 2013.

RIBEIRO, Olívia Cristina Ferreira. Ferreira. Um estudo das políticas públicas de lazer de Brotas/SP. Licere, Belo Horizonte, v. 16, n. 3, 2013.

SABATIER, P. Top-down and bottom-up approaches to implementation research: a critical analysis and suggested synthesis. Journal of Public Policy, v. 6, p. 21-48. 1986.

SANTOS, E. S.; HIRATA, E. Investimento na função desporto e lazer por níveis do Índice de Desenvolvimento Humano. Caderno de Educação Física, v. 15, p. 49-55, 2017.

SANTOS, E.S.S.; FREITAS, A.L.C. O direito ao desporto: Justiça Social e Políticas Públicas. Direitos Fundamentais e Justiça, Porto Alegre, ano 9, n.30, p. 139-157, 2015.

SANTOS, E.S.S.; STAREPRAVO, F.A.; SOUZA NETO, M.S. Programa Segundo Tempo e o vazio assistencial na região nordeste. Movimento, Porto Alegre, v. 21, n. 3, p. 759-771, 2015 .

SANTOS, F.C. Procurando o lazer na constituinte: sua inclusão como direito social na Constituição de 1988. Movimento, Porto Alegre, v. 20, n. 4, p. 1305-1327, 2014.

SILVA, Temistocles Damasceno; COUTO, Ana Marcela Santos; SANTOS, Mario Lucas Alves. Analysis of the administrative structure and financial sport in IPIAU-BA county. Podium: Sport, Leisure and Tourism Review, v. 3, n. 3, p. 77-88, 2014. 
SOUZA, C. Intermediação de Interesses Regionais no Brasil: O Impacto do Federalismo e Descentralização. Dados, Rio de Janeiro, v. 41, n. 3, 1988.

VENTURIM, Lorenza Falchetto; BORGES Carlos Nazareno Ferreira; SILVA, Dirceu Santos. Estratégias de gestão pública na prefeitura de Vitória/ES? O PELC e a intersetorialidade das ações. Licere, Belo Horizonte, v. 16, n. 4, p. 1-38, dez. 2013.

VERONEZ, L. F. C. O planejamento governamental e o orçamento do setor esportivo. In: CONGRESSO BRASILEIRO DE CIÊNCIAS DO ESPORTE E II CONGRESSO INTERNACIONAL DE CIÊNCIAS DO ESPORTE, 15., 2007, Recife. Anais... Recife, 2007.

Recebido em: 20/04/2018

Revisado em: 03/07/2018

Aprovado em: 11/07/2018

Endereço para correspondência:

edmilson.santos@univasf.edu.br

Edmilson Santos dos Santos

Universidade Federal do Vale do São Francisco, Colegiado de Educação Física.

Av. José de Sá Maniçoba, S/N

Centro

56304917 - Petrolina, PE - Brasil 